WellBeing International

WBI Studies Repository

1997

\title{
Experience in Substrate-Enriched and Substrate-Impoverished Environments Affects Behaviour of Pigs in a T-Maze Task
}

\author{
Michael Mendl \\ Scottish Agricultural College \\ Hans W. Erhard \\ Scottish Agricultural College \\ Marie Haskell \\ Scottish Agricultural College \\ Françoise Wemelsfelder \\ Scottish Agricultural College \\ Alistair B. Lawrence \\ Scottish Agricultural College
}

Follow this and additional works at: https://www.wellbeingintlstudiesrepository.org/acwp_asie

Part of the Agribusiness Commons, Animal Studies Commons, and the Operations and Supply Chain Management Commons

\section{Recommended Citation}

Mendl, M., Erhard, H. W., Haskell, M., Wemelsfelder, F., \& Lawrence, A. B. (1997). Experience in substrateenriched and substrate-impoverished environments affects behaviour of pigs in a T-maze task. Behaviour, 134(9), 643-659.

This material is brought to you for free and open access by WellBeing International. It has been accepted for inclusion by an authorized administrator of the WBI Studies Repository. For more information, please contact wbisr-info@wellbeingintl.org.

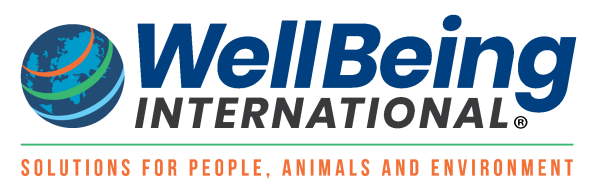




\title{
Experience in Substrate-Enriched and Substrate- Impoverished Environments Affects Behaviour of Pigs in a T-Maze Task
}

Michael Mendl, Hans W. Erhard, Marie Haskell, Françoise Wemelsfelder, and Alistair B. Lawrence Scottish Agricultural College

\begin{abstract}
Previous research showed that pigs reared in substrate-impoverished conditions performed a smaller proportion of their total behavioural repertoire in their home pens (showed lower behavioural diversity), than pigs reared in substrate-enriched conditions. This study examined whether these differences were the result of fundamental changes in behavioural organisation. A T-maze task was used to test the hypothesis that substrate-impoverished pigs are prone to develop fixed, unvarying behaviour which may underlie their reduced behavioural diversity. They were predicted to be poorer at reversing previous response patterns in the maze, and less able to alter their behaviour in response to a novel (distracting) stimulus. Female pigs were housed singly for five months in substrate-impoverished pens with bare concrete floors $(N=10)$ or substrate-enriched pens with straw and other foraging material $(N=10)$. The pigs were then trained to negotiate a $T$-maze to reach a food source. There were no differences in responses to a distracting stimulus in the start arm of the maze but, contrary to expectation, substrateenriched pigs were less able to change their behaviour when the route to food was switched. Thus, the hypothesis was not supported. During training trials, substrate-enriched pigs moved fairly rapidly to the food while substrate-impoverished pigs spent more time investigating the maze; their motivation to 'explore' the maze appeared to override their interest in food. The rapid, food-directed behaviour of the substrate-enriched pigs probably became more fixed and routine-like than the more exploratory behaviour of the substrate-impoverished pigs. The apparent importance of exploration to pigs reared in substrateimpoverished environments suggests that such conditions provide inadequate stimulation.
\end{abstract}

\section{Introduction}

Using techniques from information theory, Haskell et al. (1996) showed that female pigs housed individually for five months in substrate-enriched and substrate-impoverished environments differed in the relative diversity of the behaviour they showed under these conditions. Pigs reared in environments containing a variety of foraging substrates tended to perform a higher proportion of their total possible behavioural repertoire, as defined by a comprehensive ethogram including postural, locomotor and substrate-directed behaviour patterns, and performed a significantly higher proportion of total possible manipulative behaviours, than pigs reared in environments lacking such substrates.

There are at least two possible explanations for these differences in behavioural diversity. First, the differences were purely the result of the immediate testing environments, the home pens. The unstimulating nature of the substrate-impoverished home pens may have motivated pigs to express a proportionately lower number of behaviour patterns than in the substrate-enriched environments. 
Alternatively, and more interestingly, experience of living in these two environments over a period of months may have led to long-lasting, fundamental differences in the way in which the pigs' behaviour was organised. For example, lower levels of diversity in the behaviour of substrate-impoverished pigs may have been the result of the development of more fixed and unvarying patterns of behavioural expression (cf. Stolba et al., 1983). Other researchers have suggested that experience of impoverished environments can lead to fundamental changes in behavioural organisation such as a decrease in the individual's ability to inhibit behavioural responses and to switch between behaviour patterns (Einon et al., 1978; Fagen, 1982; Renner \& Rosenzweig, 1987). Such changes might also result in a decrease in behavioural diversity.

If this second type of explanation is correct, we would expect differences in the behavioural organisation of substrate-impoverished and substrate- enriched pigs to be evident in contexts quite different to the home pen environments. In this study, we set out to examine this possibility by investigating the behaviour of pigs in a test situation outside the home pen, in which we could obtain some direct measures of aspects of behavioural organisation that might underlie the differences in behavioural diversity reported by Haskell et al. (1996). We used a T-maze task to measure how fixed and unvarying a pig's behaviour was, and how easily the pig could inhibit previous response pattems to allow the expression of new behaviour. The task involved the acquisition of a simple spatial discrimination, followed by probe distraction and reversal tests to examine how readily the pigs altered their behaviour to respond to a novel stim- ulus, and how readily they shifted from one spatial response to another (cf. Benus et al., 1987). If the apparent lowered behavioural diversity of substrate-impoverished pigs was due to an increase in their propensity to show fixed, unvarying behaviour, we hypothesised that they would change their behaviour less readily when subjected to the distraction and reversal tests than would substrateenriched pigs. If so, we could extend Haskell et al.'s (1996) conclusions to suggest that differences in behavioural diversity in pigs housed in different environments were likely to be due to fundamental changes in behavioural organisation, as opposed to being a consequence of the immediate environmental conditions in which they were observed.

\section{Methods}

\section{Subjects, housing and care}

The subjects were 20 of the 26 Large White $\times$ Landrace female pigs studied by Haskell et al. (1996). Each pig was housed individually in a pen measuring $2 \times 3 \mathrm{~m}$ from the age of ca 10 weeks until testing at ca 28 weeks. Full details of housing are given in Haskell et al. (1996). Briefly, ten of the pigs were housed in substrate-impoverished pens with bare concrete floors. The other 10 pigs were housed in substrateenriched pens containing approximately $4 \mathrm{~kg}$ of straw, $5 \mathrm{~kg}$ of forest bark, and two tree branches. Pigs had visual contact with animals in their treatment group, but not with those in the other treatment group. All pens contained a water drinker and food trough, and the pigs had an ad libitum supply of both water and food. Food was provided at 08:30 h each day and pens cleaned out at 09:00 $\mathrm{h}$. The bare concrete floors were scraped clean, and dirty straw and bark was removed and replaced with clean material. Branches were replaced monthly.

\section{Procedure}

T-maze tests started two to three weeks after all observations reported in Haskell et al. (1996) had been completed. The pigs were ca 7 months old at this time and their mean weight was $151.2 \mathrm{~kg}$. Two days prior to the start of testing, food was removed at 17:20 $\mathrm{h}$ from the home pen of the pigs to be tested. At 16:00 $\mathrm{h}$ the following day, $5.5 \mathrm{~kg}$ of food was provided. An observer recorded the feeding behaviour of the pigs for the next $80 \mathrm{~min}$. An instantaneous sampling technique was used to record whether a pig was 
feeding or not feeding. Samples were made at one minute intervals. At 17:20 h recording stopped, the food troughs were removed from the home pens and the remaining food weighed. In nearly all cases, pigs fed continuously from the moment that food was provided until some time at which they appeared satiated. They then stopped feeding and rarely started again. Consequently, it was possible to estimate a feeding rate by dividing the amount of food consumed by the number of samples (minutes) during which the pig was observed to be feeding. This feeding procedure was continued on each of the following days of maze-tests.

A plan of the T-maze is given in Fig. 1. The maze comprised a start arm and a right and left arm, one of which lead to a food reward and the exit of the maze. For five of the pigs from each treatment, food was reached by turning into the left arm. For the other five pigs from each treatment, a right turn was rewarded. On a pre-test run, prior to the first trial, each pig was taken from its home pen to the start arm of the maze and then guided through the maze first to the unrewarded arm, and then to the arm where the food and exit were located. The pig was allowed to feed for about $15 \mathrm{~s}$, and then returned to its home pen. On all subsequent trials, the pig was taken to the start arm, negotiated the maze on its own, and was allowed to feed for about $15 \mathrm{~s}$. Trials were run in morning (10:00-12:30 h) and afternoon (13:00-15:30 h) sessions over three consecutive days. Following the pre-test run, three trials were run for each pig on the morning of the first day, and five more during the afternoon. On the second day, five more trials were run in the morning. In the afternoon, one normal trial (the last 'training' trial) was run followed by three 'distraction' trials in which a distracting stimulus of a white strip of tape (length $1 \mathrm{~m}$, width $5 \mathrm{~cm}$ ) was stuck to the floor across the start arm at the position shown in Fig. 1. On the morning of the third day, two normal trials were run. In the afternoon, one normal trial was run followed by six 'reversal' trials in which the rewarded and unrewarded arms were reversed.

A maximum of eight pigs were tested in each three-day-block of trials. During each session, pigs were tested in pairs; one pig coming from each treatment group. Thus, a pig from the substrate-enriched environment would perform a maze trial, followed by a pig from the substrate-impoverished environment. These pigs would alternate until they had completed the required number of trials for the session. The order in which pairs were tested was selected randomly but remained the same across all sessions of trials.

Behaviour during each trial was recorded using the Keybehaviour and Keytime programs (Deag, 1993) by an observer on an observation gantry overlooking the maze. The observer recorded the time at which the pig left its home pen (all four legs outside the pen), the time at which it entered the start arm of the maze (all four legs inside the maze), all subsequent times at which it entered the left arm, right arm or start arm (an entry to these arms was recorded when the pig moved its two front legs across the boundary lines indicated on Fig. 1), the time at which it found food, whether it ate the food or not, the time at which it left the maze (all four legs outside the maze), and the time at which it returned to its home pen (all four legs inside the pen). Any occurrences of defaecation or urination in the maze were recorded during training trials as indicators of how settled the animals were. In addition, during the three trials preceding the distraction tests, the observer recorded the amount of time that the pig spent nosing the area where the white strip was to be placed. During the distraction trials, the observer recorded the amount of time spent nosing the strip.

Non-parametric statistics were used to analyse the effect of treatment on latencies to make a decision (the time at which the pig moved from the start arm to the right or left arm), the total number of arms entered during a trial (entry to two arms only (the start arm and the rewarded arm) indicates perfect performance), and other behavioural data. Parametric tests were used to analyse the weight and food consumption data. 


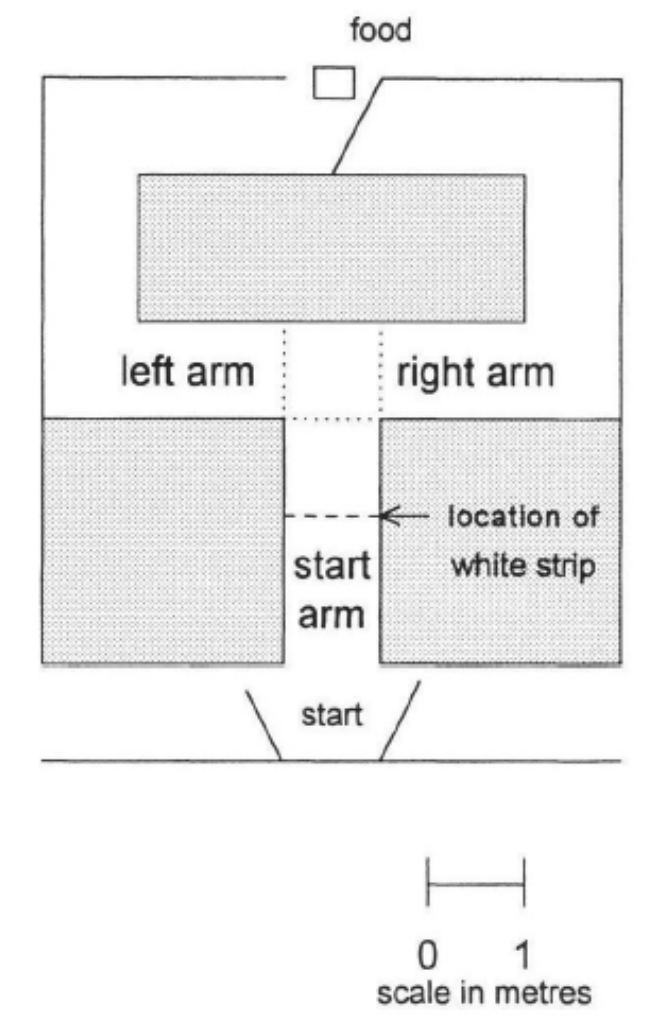

Fig. 1. Plan of the T-maze apparatus. Pigs entered the maze at the start point of the start arm. They moved up this arm and could then enter either the left or right arm. All entries to arms were recorded when pigs placed their front two feet over the imaginary arm boundaries (indicated by dotted lines on the figure). The door at the exit of the maze could be moved to allow pigs to access the food trough and the exit of the maze via either the left or right arm. In the figure, a turn to the left is rewarded. During distraction trials, a white strip of tape was stuck to the floor of the start arm at the location indicated.

\section{Results}

Three of the 20 pigs (two from the substrate-impoverished and one from the substrate-enriched condition) were eliminated from the analysis because they appeared to be entering their first oestrus during the testing period, became very difficult to move between the home pen and maze, and often stood still for several minutes once they had entered the maze.

\section{Training trials}

The first 14 trials, excluding the pre-test run in which pigs were guided round the maze, involved the pigs becoming familiar with the task. Mean latencies to make a decision (move from the start arm to the right or left arm of the maze) are shown in Fig. 2. As can be seen, the substrate- impoverished pigs took significantly longer to make a decision on trials $3,6,10,11$ and 12, and had a higher mean decision latency across all 14 trials. Informal observation indicated that substrate-impoverished pigs spent more time nosing the floor and walls of the maze than did substrate-enriched pigs. They also took significantly longer than substrate-enriched pigs to arrive at the food/exit of the maze on trials 4-7, 9-13 and across all 14 trials (Fig. 3). Frequencies of defaecation and urination in the maze were very low and did not differ between the two groups (mean frequency/trial SEM) across all 14 trials: defaecation - enriched, 0.0238 
$( \pm 0.017)$; impoverished, $0.0982( \pm 0.063)$; urination - enriched, $0( \pm 0)$; impoverished, $0.0357( \pm 0.027)$; Mann-Whitney $U$ tests, $p>0.05)$.

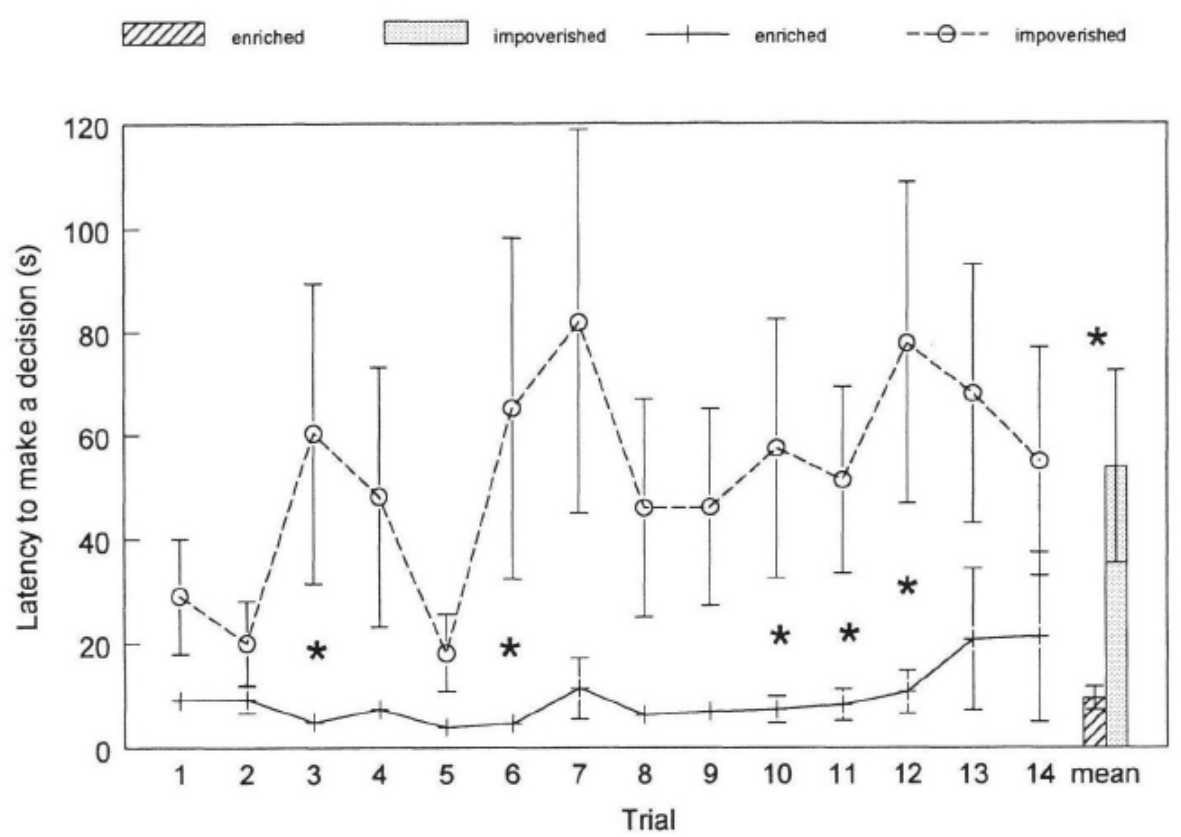

Fig. 2. Mean latencies (s) (it: SEM) to make a decision (move from the start arm into the left or right arm) on each of the 14 training trials, and averaged across all 14 trials for the substrate-enriched (solid line, striped bar) and substrate-impoverished (broken line, stippled bar) pigs. Asterisks indicate significant differences between the two experimental groups (Mann-Whitney $U$ tests, ${ }^{*} p<0.05$ ).

On each trial, the number of pigs feeding from the trough at the end of the maze was recorded. During trials 8-12, fewer pigs from the substrate- impoverished environments fed than did pigs from the substrate-enriched environments $\left(x^{2}\right.$ tests, $\left.p<0.05\right)$. This suggests that, during these trials

at least, substrate-impoverished pigs were less interested in the food than substrate-enriched pigs. This may have been due to a general difference in feeding motivation between the two treatment groups. Pigs from the two treatments did not differ in body weight (substrate-enriched: $154.6 \mathrm{~kg}$ (SEM 3.8); substrateimpoverished; $147.5 \mathrm{~kg}$ (SEM 4.5); $t=1.19, d f=14, p=0.25$ ) and, at the end of each day of testing, they consumed similar amounts of food (Table 1). However, there was a tendency for substrate- enriched pigs to consume their food faster, and this nearly reached significance when analysed across all four days on which food intake was observed (Table 1). If rate of food consumption can be used as a mea- sure of feeding motivation (cf. Terlouw et al., 1991), this provides some support for the hypothesis that substrateimpoverished pigs were slower to move around the maze because they were less motivated to reach the food incentive at the end of the maze. If this was the case, we might expect substrate-impoverished pigs to have been generally less interested in going to the maze. In fact, they appeared to find the maze as attractive as did substrate-enriched animals; on every trial except trial 8, the speed at which they moved from the home pen to the maze (time taken to reach the maze/distance travelled) was no different to that of substrate-enriched animals (Mann-Whitney $U$ tests, $p>0.05$ ). There were also no between- group differences in the speed of movement from the maze to the home pen (Mann-Whitney $U$ tests, $p>0.05$ ). 


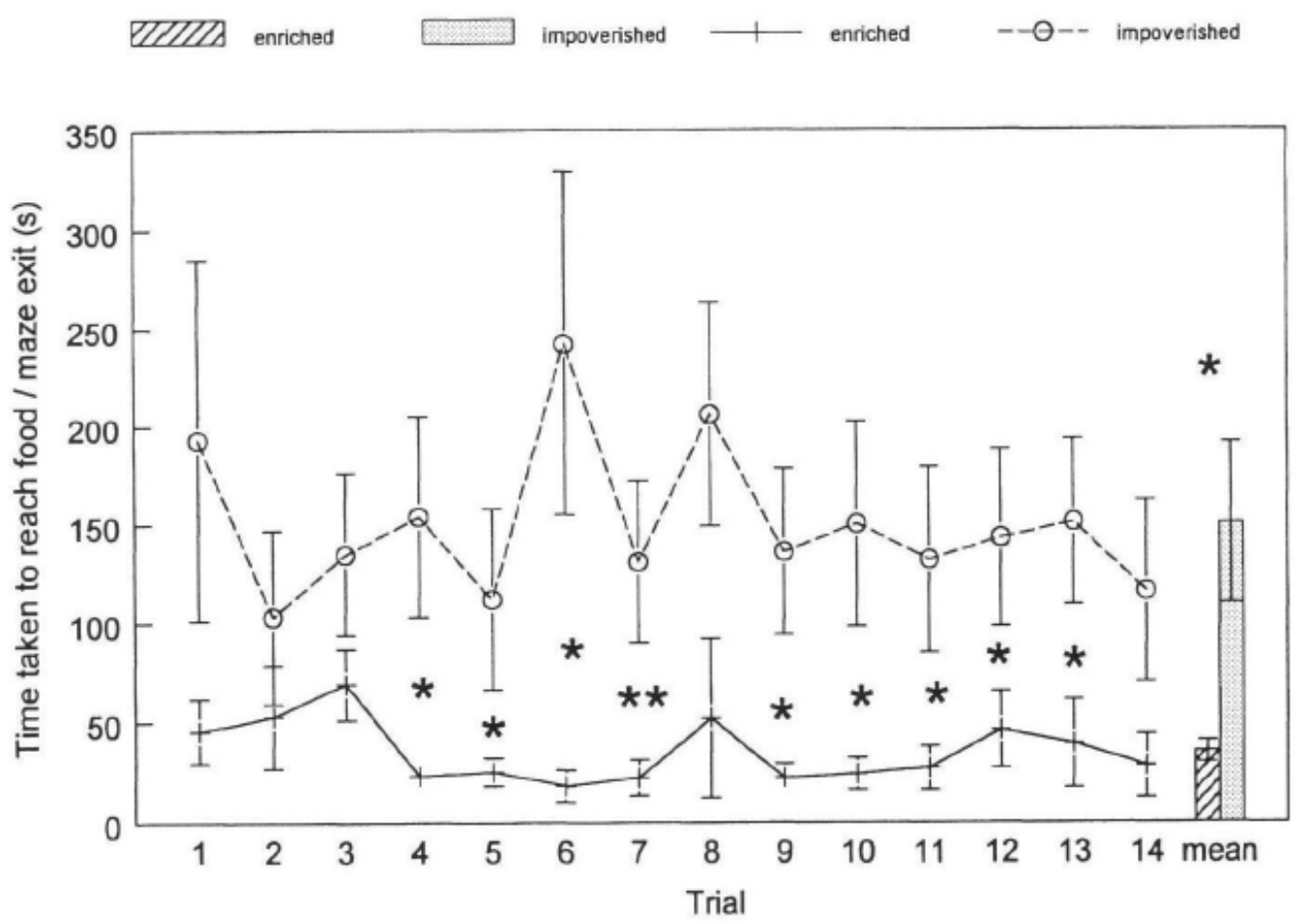

Fig. 3. Mean time (s) ( \pm SEM) to reach food/maze exit (i.e. time spent in the maze) on each of the 14 training trials, and averaged across all 14 trials for the substrate-enriched (solid line, striped bar) and substrateimpoverished (broken line, stippled bar) pigs. Asterisks indicate significant differences between the two experimental groups (Mann-Whitney U tests, ${ }^{* *} p<0.01,{ }^{*} p<0.05$ ).

The mean number of maze arms entered on each trial is shown in Fig. 4. A pig performing the task correctly would enter only two arms (the start arm and the rewarded arm). On trial 6, and across all 14 trials, substrate-impoverished animals entered significantly more arms than substrate-enriched animals.

\section{Distraction trials}

The distraction trials provided one way of testing the hypothesis that pigs reared in substrateimpoverished conditions were less able to alter their ongoing behaviour to respond to an external stimulus, and more likely to behave in a fixed and unvarying manner. The prediction was that they would be less easily distracted by changes in the external environment; the distraction stimuli would have little or no effect on the time they took to move through the start arm to the decision point. Latencies before and during the distraction trials were compared within each treatment group. Table 2 shows the mean decision latencies, and the mean time spent nosing the white strip or the area where it was to be placed, during the three trials preceding the distraction trials (trials 12-14; see Fig. 2), and during the three distraction trials themselves (trials 15-17) for each treatment group separately. Pigs varied in the extent to which they responded to the novel stimulus. Substrate-enriched pigs tended to show an increase in time spent nosing the white strip relative to the time they spent during preceding trials nosing the area where the strip was to be placed. The opposite tendency was evident for substrate-impoverished pigs. However, in both treatment groups, no significant effects were observed. Similarly, in both treatment groups there was no evidence that the distraction stimulus caused pigs to make errors and enter more arms during the distraction trials than during the preceding training trials (Table 2). 
TABLE 1. Food consumption and feeding rate of pigs

\begin{tabular}{|c|c|c|c|c|c|c|c|}
\hline \multirow[t]{2}{*}{ Measure } & \multicolumn{2}{|c|}{ Substrate-enriched } & \multicolumn{2}{|c|}{ Substrate-impoverished } & \multicolumn{3}{|c|}{$t$-tests } \\
\hline & mean & SEM & means & SEM & $t$ & df & $p$ \\
\hline \multicolumn{8}{|l|}{ Food consumed $(\mathrm{kg})$} \\
\hline Day preceding trials & 3.30 & 0.26 & 3.18 & 0.50 & 0.21 & 11 & 0.841 \\
\hline Trial day 1 & 3.30 & 0.41 & 2.51 & 0.32 & 1.51 & 14 & 0.153 \\
\hline Trial day 2 & 3.01 & 0.30 & 2.87 & 0.30 & 0.35 & 14 & 0.733 \\
\hline Trial day 3 & 3.02 & 0.32 & 3.14 & 0.26 & -0.27 & 14 & 0.790 \\
\hline Mean across all days & 3.16 & 0.28 & 2.92 & 0.32 & 0.55 & 14 & 0.590 \\
\hline \multicolumn{8}{|l|}{ Feeding rate ( $\mathrm{g} / \mathrm{min})$} \\
\hline Day preceding trials & 92.2 & 7.74 & 73.6 & 4.75 & 2.05 & 13 & 0.061 \\
\hline Trial day 1 & 107.9 & 14.35 & 79.3 & 5.72 & 1.85 & 11 & 0.093 \\
\hline Trial day 2 & 99.0 & 8.55 & 79.7 & 4.26 & 2.02 & 12 & 0.067 \\
\hline Trial day 3 & 90.8 & 4.41 & 81.0 & 4.61 & 1.53 & 14 & 0.147 \\
\hline Mean across all days & 97.5 & 7.52 & 78.4 & 4.69 & 2.15 & 13 & 0.051 \\
\hline
\end{tabular}

VIIID enriched $\square$ impoverished $\square-1-$ enriched $-\Theta--$ impoverished

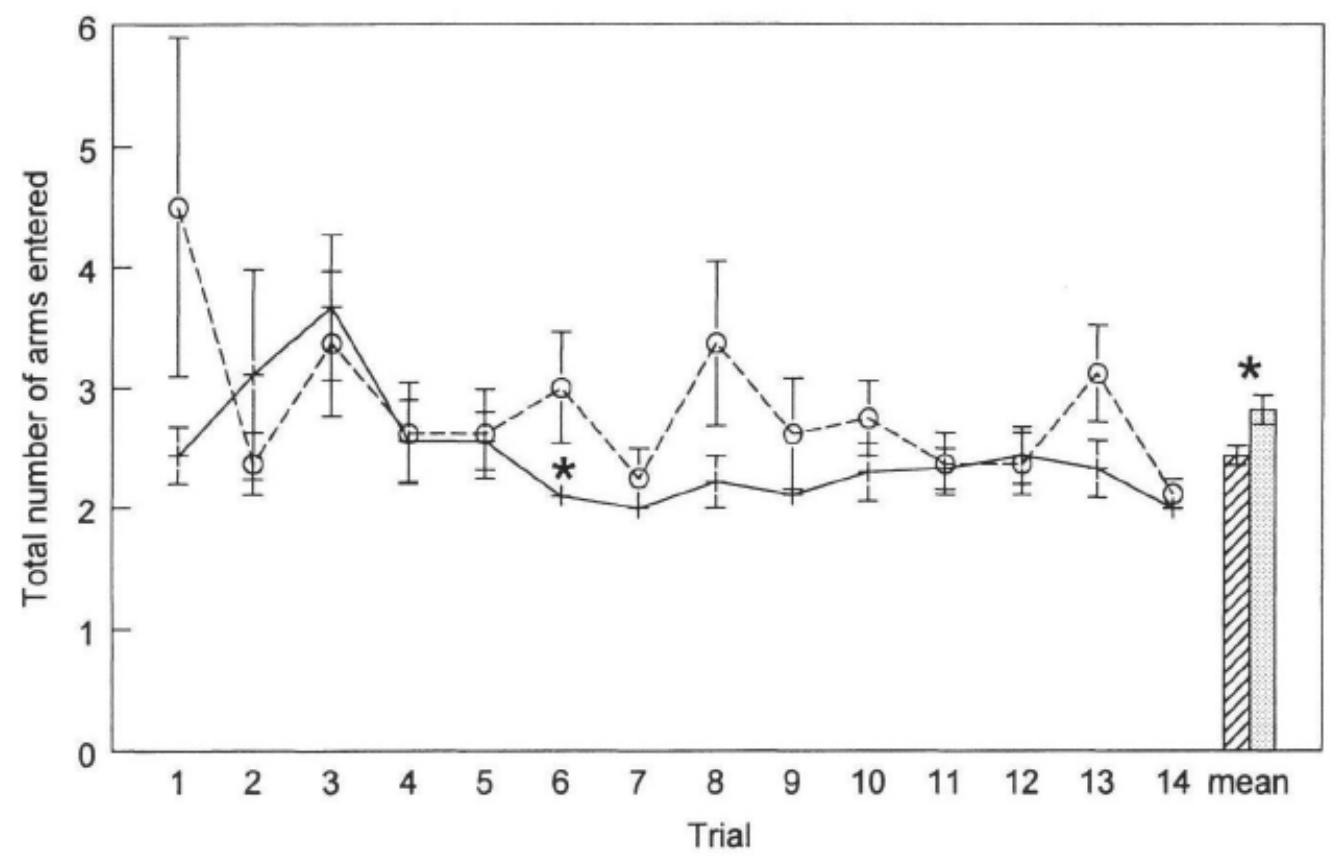

Fig. 4. Mean number of maze arms entered on each of the 14 training trials, and averaged across all 14 trials for the substrate-enriched (solid line, striped bar) and substrate-impoverished (broken line, stippled bar) pigs. Asterisks indicate significant differences between the two experimental groups (Mann-Whitney $U$ tests, $\left.{ }^{*} p<0.05\right)$. 
TABLE 2. Behaviour preceding and during the distraction trials

\begin{tabular}{|llccc|}
\hline Measure & \multicolumn{3}{c}{ Substrate-enriched } & \multicolumn{2}{c|}{$\begin{array}{c}\text { Substrate-impoverished } \\
\text { mean }\end{array}$} & SEM & mean & SEM \\
\hline Mean decision latency (s) & & & & \\
Trials 12-14 preceding distraction trials & 17.5 & 8.5 & 66.9 & 24.5 \\
Distraction trials (trials 15-17) & 10.9 & 3.2 & 57.5 & 17.9 \\
Wilcoxin tests & $(Z=-0.28, p=0.78)$ & $(Z=-0.51, p=0.61)$ \\
Mean time spent nosing the white strip or the & & & & \\
area where it was to be placed (s) & & & & \\
Trials 12-14 preceding distraction trials & 1.0 & 0.7 & 37.4 & 13.7 \\
Distraction trials (trials 15-17) & 3.0 & 0.71 & 16.54 & 4.98 \\
Wilcoxin tests & $(Z=-1.68, p=0.09)$ & $(Z=-1.82, p=0.07)$ \\
Mean number of arms entered & & & & \\
Trials 12-14 preceding distraction trials & 2.26 & 0.15 & 2.54 & 0.19 \\
Distraction trials (trials 15-17) & 2.04 & 0.04 & 2.33 & 0.21 \\
Wilcoxin tests & $(Z=-1.0, p=0.32)$ & $(Z=-1.34, p=0.18)$ \\
\hline
\end{tabular}

QZIZ) enriched $\square$ impoverished $\square$ enriched $\quad-\ominus--$ impoverished

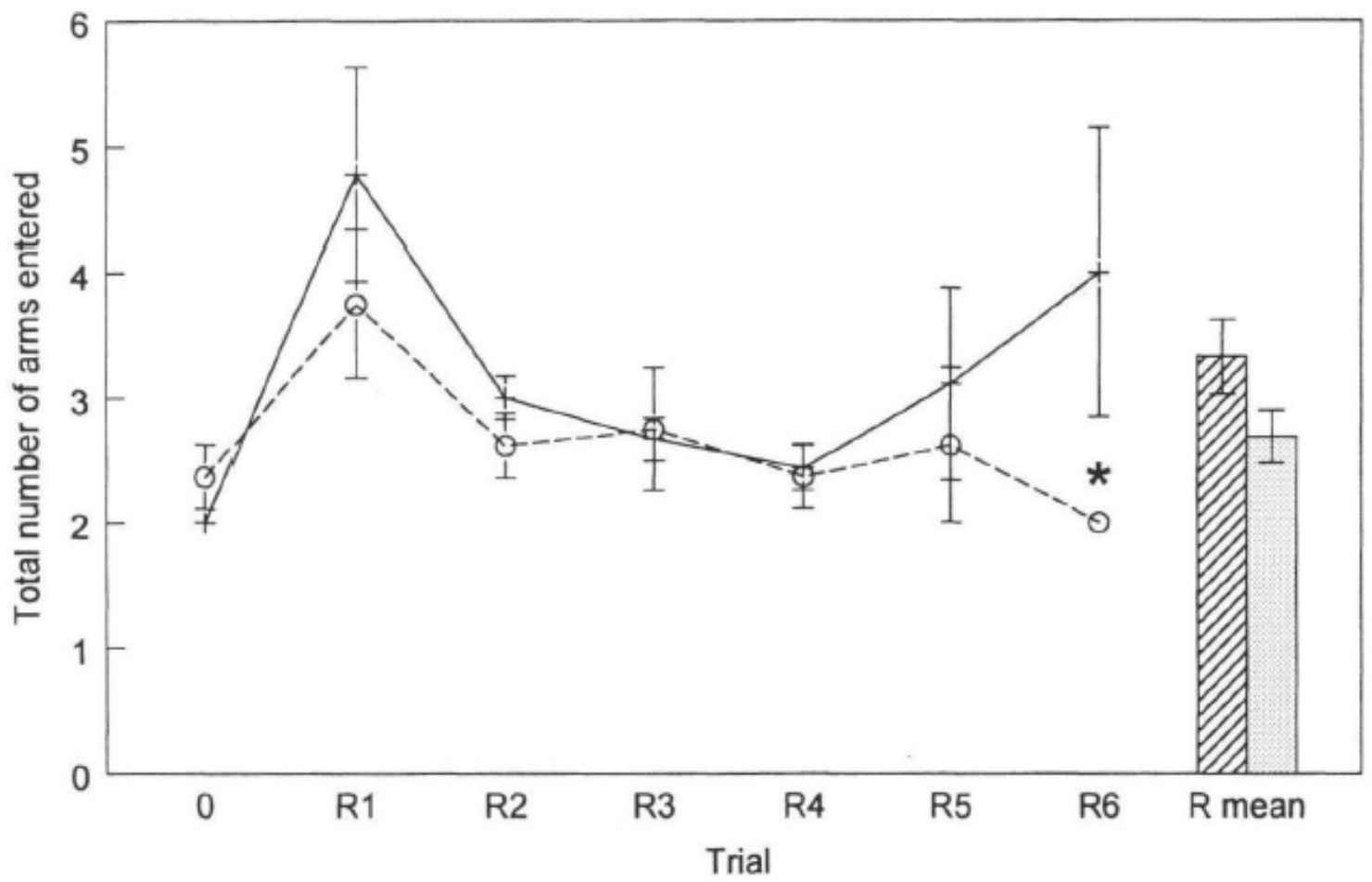

Fig. 5. Mean number of maze arms entered on the trial preceding the first reversal trial (trial 0 ), each of the 6 reversal trials (trials R I -R6), and averaged across all 6 reversal trials (R mean) for the substrate-enriched (solid line, striped bar) and substrate-impoverished (broken line, stippled bar) pigs. Asterisks indicate significant differences between the two experimental groups (Mann-Whitney $U$ tests, ${ }^{*} p<0.05$ ). 


\section{Reversal trials}

The hypothesis tested here was that substrate-impoverished pigs would be more fixed in their behaviour and slower to inhibit their previous response in the maze, and to shift to a new response. During this stage of the experiment, pigs from both groups did not differ in their decision latencies, except during the first and third reversal trials (Mann-Whitney $U$ tests, $p>0.05$ ). Figure 5 shows that both groups of pigs increased the number of arms entered on the first reversal trial (trial R1). However, the increase relative to the preceding trial (trial 0 ) was only significant for pigs in the substrate-enriched group (Wilcoxon test: $Z=-2.52 ; N=8, p=0.0117$ ). These animals appeared to make repeated errors, making on average three extra errors during trial RI relative to the average one extra error made by substrate-impoverished pigs (Fig. 5). On the following trials, the number of arms entered decreased once more. By the sixth reversal trial, substrate-impoverished pigs were performing without errors (only two arms entered). On the other hand, substrate-enriched pigs appeared to adopt the new spatial response, and then to revert back to the response they made during the RI trial, such that by the sixth reversal trial they were making more errors and entering significantly more arms than the substrate-impoverished pigs.

\section{Discussion}

This study set out to examine the hypothesis that pigs reared in substrate- impoverished environments have a greater propensity to develop fixed, unvarying behaviour and are less able to inhibit behavioural responses or to switch from one behaviour to another, than pigs reared in substrate- enriched conditions. Results of the distraction and reversal trials did not support this hypothesis. There was no significant effect of the distraction stimulus on the behaviour of pigs from either housing condition. In addition, and contrary to expectation, substrate-enriched pigs appeared to have more difficulty in suppressing their previous responses during the first reversal trial than substrate-impoverished pigs, and also appeared to revert back to their original responding pattern after several trials.

This second finding suggests that, if anything, it was substrate-enriched pigs who showed a greater propensity to develop fixed, unvarying behaviour and to be less able to inhibit and change previous response patterns. This is in direct contrast to our hypothesis and indicates that differences in measures of behavioural diversity expressed in the home pen were not related in the expected way to differences in behavioural organisation as measured in the reversal and distraction tests. More generally, the results also contrast with findings from other species, principally rodents, which indicate that the abilities to inhibit or reverse previous response patterns are usually less evident in animals reared in impoverished environments (e.g. Luchins \& Forgus, 1955; Morgan, 1973; Morgan et al., 1977; Einon et al., 1978; Renner \& Rosenzweig, 1987).

These unexpected results may be explained by reference to the differences in the reaction of substrateimpoverished and substrate-enriched pigs to the maze environment itself during the training trials. Substrate-enriched pigs moved fairly rapidly to the food, while substrate-impoverished pigs spent considerably more time in the maze, entered more arms, and were less likely to feed on exiting the maze. Van Woerden (1986) also observed that rats reared in impoverished environments were slower to move down a runway to a food dish than those from enriched environments (but see Morgan, 1973). As argued earlier (see Results section), it seems unlikely that this difference was solely due to a difference in feeding motivation of pigs from the two treatments (cf. Morgan, 1973). Although substrate-enriched pigs tended to eat their daily food ration faster than substrate-impoverished pigs, there were no differences in the mean body weights of both treatment groups or in the mean amounts of food that they consumed.

The differences may have reflected poorer spatial abilities in the substrate-impoverished pigs (cf. Einon, 1980). However, the fact that substrate- impoverished pigs made, on average across the 14 training trials, 
1.15 times as many arm entries or 'errors' (2.82 vs 2.44$)$ as substrate-enriched pigs (Fig. 4) is unlikely to account for the fact that they spent an average of 4.26 times as long in the maze (150.3 vs $35.3 \mathrm{~s}$; Fig. 3). The maze was relatively small (see Fig. 1), so it seems highly unlikely that the relatively large amount of time spent in it by the substrate-impoverished pigs reflected an inability to locate the correct exit point. Instead, informal observations suggested that these pigs spent their time nosing the maze floor and walls. The possibility that substrate-impoverished pigs were more fearful of the maze environment and showed freezing behaviour and caution in proceeding through it should also be considered. Such effects of rearing in impoverished environments have been suggested previously (e.g. Jones \& Waddington, 1992), and could be due to a general lack of stimulation in the home environment resulting in sensitisation to and heightened fear of novelty. However, levels of defaecation and urination, which may indicate fearfulness, were low and did not differ between the two groups. Informal observations also suggested that freezing behaviour and distress vocalisations occurred rarely in the maze. In addition, there was no evidence that substrate-impoverished pigs moved more slowly to the maze from their home pens, or that they moved more rapidly from the maze back to the home pens, as might have been expected if they found the maze aversive (cf. Rushen, 1986).

On the basis of the above, it can be argued that both groups of pigs found the maze equally attractive, in that they did not differ in the speed at which they moved to it from their home pen. However, once in the maze, substrate-enriched pigs focused on getting to the food while substrate- impoverished pigs appeared to be more interested in investigating the maze itself. One possible consequence of this is that the 'food goal' focus of the substrate-enriched pigs resulted in them developing a rapid, food-directed response which became routine-like and tended to persist during the reversal test. Substrateimpoverished pigs, who were more interested in the maze itself than the food, were less susceptible to developing this type of fixed behaviour. Thus, the different reponses to the maze environment may underlie the unexpected findings of the reversal test.

The apparent increased investigatory behaviour in the substrate-impoverished pigs suggests that, assuming both groups of pigs to be equally hungry (see earlier), the motivation of these pigs to 'explore' the maze overrode their interest in food, while this was not the case for substrate-enriched pigs. Other studies have also suggested that rearing in impoverished environments can result in higher levels of apparently exploratory behaviour in a novel environment (e.g. rats: Woods et al., 1960; pigs: Wood-Gush et al., 1990; Pearce \& Paterson, 1993).

Higher levels of both 'extrinsic' and 'intrinsic' exploration (Berlyne, 1960) might have been expected for substrate-impoverished pigs. Extrinsic exploration corresponds to the appetitive component of a specific motivational system and is directed towards a biologically significant event such as feeding (Berlyne, 1960; Wood-Gush et al., 1990). Given that substrate- impoverished pigs were reared in the absence of straw, which pigs appar- ently have inelastic demand for (see Matthews, 1991), it is possible that the higher amounts of time spent in the maze environment reflected exploration for a manipulable foraging substrate (cf. Nicol \& Guilford, 1991).

Intrinsic exploration appears to be unrelated to a specific consummatory act and is seemingly an end in itself, serving to familiarise the animal with its environment (Berlyne, 1960). If intrinsic exploration depends upon the disparity between expected and actual sensory inputs and functions to gather information about novelty (e.g. Inglis, 1983), it is reasonable to propose that the contrast between the stimulation offered by the home pen and the more complex maze environment was greater for substrateimpoverished pigs than for substrate-enriched pigs and thus resulted in higher levels of exploration. The lack of opportunity for pigs to express intrinsic exploratory behaviour in impoverished home environments (see Pearce \& Paterson, 1993; Beattie et al., 1995) could also lead to an in- crease in endogenous sources of exploratory motivation (cf. Wood-Gush \& Vestergaard, 1991). 
The sustained level of apparent exploratory behaviour by substrate-impoverished pigs across the 14 training trials (Fig. 3) parallels the finding that rats reared in impoverished environments show a slow decline in exploratory behaviour (Inglis, 1975), and are slower to habituate to novel stimuli (e.g. Einon et al., 1975; Einon \& Morgan, 1976).

In conclusion, experience of different environments had a marked effect on the way in which the pigs responded to the maze testing situation. Substrate-enriched pigs focused on the food 'goal' of the maze while substrate-impoverished pigs appeared to prefer exploring the maze. The food goal focus of the substrate-enriched pigs probably predisposed them to develop a rapid, food-directed response which was less readily altered during the reversal test than the more exploratory behaviour of the substrateimpoverished pigs. On the basis of these findings, it is difficult to provide a conclusive explanation for the differences in behavioural diversity dis- played by substrate-enriched and substrate-impoverished pigs in their home pens (Haskell et al., 1996). However, it seems likely that they were due to the nature of the immediate testing environment, or to a fundamental change in some other form of behavioural organisation not studied here (cf. Wemelsfelder et al., 1996). From an animal welfare perspective, the apparent importance of exploration to pigs reared in substrate-impoverished environments suggests that such conditions provide inadequate stimulation for these animals.

\section{Acknowledgments}

We thank Sheena Calvert, Joan Chirnside, Lesley Deans and Kirsty Mclean for looking after the pigs, and Miles Chester for helping to collect data. This study was supported by the Biotechnology and Biological Sciences Research Council, and the Scottish Office Agriculture Environment and Fisheries Department.

\section{References}

Beattie, V.E., Walker, N. \& Sneddon, I.A. (1995). Effects of environmental enrichment on behaviour and productivity of growing pigs. - Anim. Welfare 4, p. 207-220.

Benus, R.F., Koolhaas, J.M. \& van Oortmerssen, G.A. (1987). Individual differences in behavioural reaction to a changing environment in mice and rats. - Behaviour 100, p. 105-122.

Berlyne, D.E. (1960). Conflict, arousal and curiosity. - McGraw-Hill, New York.

Deag, J.M. (1993). Keytime: A program system for recording and analysing behavioural data. - Copyright John M. Deag 1987-1993, 10 Fletcher Grove, Penicuik, Midlothian, UK.

Einon, D. (1980). Spatial memory and response strategies in rats: age, sex and rearing differences in performance. - Quart. J. Exp. Psychol. 32, p. 473-489.

-- \& Morgan, M. (1976). Habituation of object contact in socially-reared and isolated rats (Rattus norvegicus). - Anim. Behav. 24, p. 415-420.

--,-- \& Kibbler, C.C. (1978). Brief periods of socialization and later behavior in the rat. - Devel. Psychobiol. 11, p. 213-225.

--, -- \& Sahakian, B.J. (1975). The development of intersession habituation and emergence in socially reared and isolated rats. - Devel. Psychobiol. 8, p. 553-559.

Fagen, R. (1982). Evolutionary issues in development of behavioral flexibility. - In: Perspectives in ethology. Vol. 5 (P.P.G. Bateson \& P.H. Klopfer, eds). Plenum Press, New York, p. 365-383.

Haskell, M., Wemelsfelder, F., Mendl, M., Calvert, S. \& Lawrence, A.B. (1996). The effect of substrateenriched and substrate-impoverished housing environments on the diversity of behaviour in pigs. - Behaviour 133, p. 741-761. 
Inglis, I.R. (1975). Enriched sensory experience in adulthood increases subsequent ex- ploratory behaviour in the rat. - Anim. Behav. 23, p. 932-940.

-- (1983). Towards a cognitive theory of exploratory behaviour. - In: Exploration in animals and humans (J. Archer \& L. Burke, eds). Van Nostrand Reinhold, London, p. 72-116.

Jones, R.B. \& Waddington, D. (1992). Modification of fear in domestic chick, Gallus gallus domesticus, via regular handling and early environmental enrichment. - Anim. Behav. 43, p. 1021-1033.

Luchins, A.S. \& Forgus, R.H. (1955). The effects of differential post-weaning environment on the rigidity of an animal's behavior. - J. Genet. Psychol. 86, p. 51-58.

Matthews, L. (1991). Behavioural deprivation: are there substitutes for the real thing? - In : Applied animal behaviour: past, present and future (M.C. Appleby, R.I. Horrell, J.C. Petherick \& S.M. Rutter, eds). UFAW, Potters Bar, p. 125-129.

Morgan, M.J. (1973). Effects of post-weaning environment on learning in the rat. - Anim. Behav. 21, p. 429-442.

--, Einon, D. \& Morris, R.G.M. (1977). Inhibition and isolation rearing in the rat: extinction and satiation. Physiol. Behav. 18, p. 1-5.

Nicol, C.J. \& Guilford, T. (1991). Exploratory activity as a measure of motivation in deprived hens. - Anim. Behav. 41, p. 333-341.

Pearce, G.P. \& Paterson, A.M. (1993). The effect of space restriction and provision of toys during rearing on the behaviour, productivity and physiology of male pigs. - Appl. Anim. Behav. Sci. 36, p. 11-28.

Renner, M.J. \& Rosenzweig, M.R. (1987). Enriched and impoverished environments. Effects on brain and behaviour. - Springer Verlag, New York.

Rushen, J. (1986). Aversion of sheep to electro-imobilisation and physical restraint. - Appl. Anim. Behav. Sci. 15, p. 315-324.

Stolba, A., Baker, N. \& Wood-Gush, D.G.M. (1983). The characterization of stereotyped behaviour in stalled sows by informational redundancy. - Behaviour 87, p. 157-182.

Terlouw, E.M.C., Lawrence, A.B. \& Illius, A.W. (1991). Influences of feeding level and physical restriction on development of stereotypies in sows. - Anim. Behav. 42, p. 981-991.

van Woerden, G.J.M. (1986). Effects of differential experience on brain and behaviour in the rat. - PhD dissertation, University of Nijmegen.

Wemelsfelder, F., Haskell, M., Mendl, M., Calvert, S. \& Lawrence, A.B. (1996). The effects of housing growing pigs with or without substrate on their responsiveness to novelty. - Proceedings of the 30th International Society for Applied Ethology Congress (I.J.H. Duncan, T.M. Widowski \& D.B. Haley, eds). Col. K.L. Campbell Center for the Study of Animal Welfare, Guelph, p. 69.

Wood-Gush, D.G.M. \& Vestergaard, K. (1991). The seeking of novelty and its relation to play. - Anim. Behav. 42, p. 599-606.

--, -- \& Petersen, H.V. (1990). The significance of motivation and environment in the development of exploration in pigs. - Biol. Behav. 15, p. 39-52.

Woods, P.J., Ruckelhaus, S.I. \& Bowling, D.M. (1960). Some effects of 'free' and 'restricted' environment rearing conditions upon adult behaviour in the rat. - Psychol. Rep. 6, p. 191-200. 